\section{Gemella morbillorum mediastinitis and osteomyelitis following transesophageal endoscopic ultrasound-guided fine-needle aspira- tion of a posterior mediastinal lymph node}

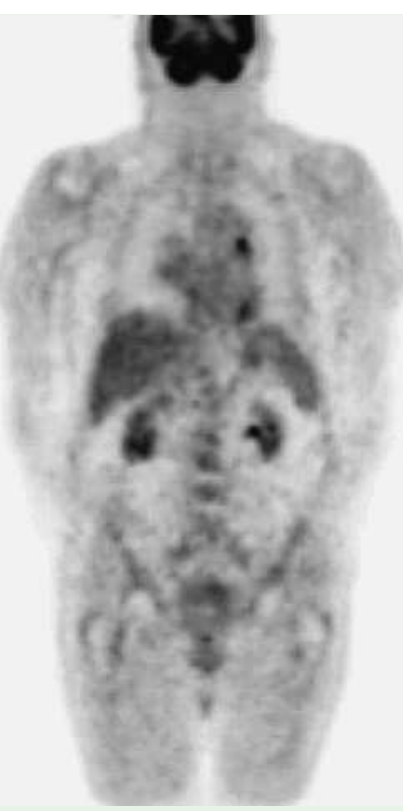

Figure 1 Positron-emission tomographic (PET) scan showing increased activity in the left mediastinum.

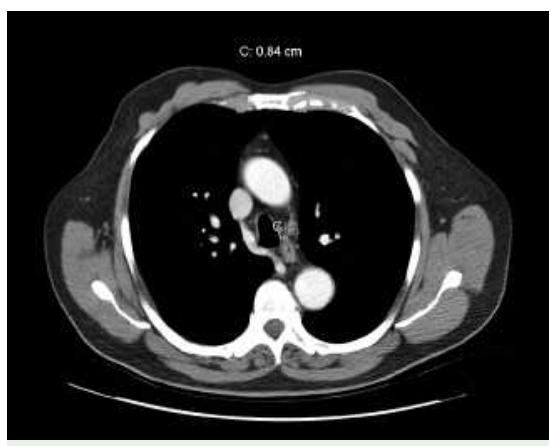

Figure 2 Computed tomographic scan showing an 8.4-mm-diameter lymph node in the posterior aortopulmonary window, corresponding to the region of increased PET activity.

A 78-year-old-man with a history of colon cancer was found on follow-up examinations (abdominal computed tomography and positron-emission tomography scans) to have an 8-mm posterior aortopulmonary-window lymph node that was suspected to be malignant ( $\bullet$ Figure 1, $\odot$ Figure 2). Radial endoscopic ultrasound (EUS) revealed a 10-mm lymph

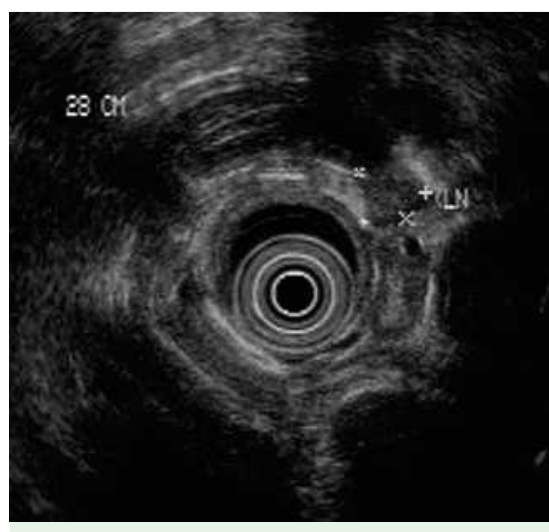

Figure 3 Radial endoscopic ultrasound view showing a left posterior aortopulmonary-window lymph node measuring $10 \mathrm{~mm}$ in diameter and located $28 \mathrm{~cm}$ from the incisors.

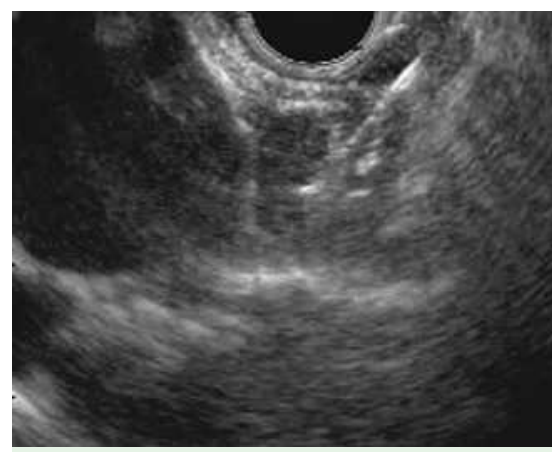

Figure 4 Transesophageal endoscopic ultrasound-guided fine-needle aspiration (EUSFNA) of the posterior aortopulmonary lymph node.

node in the posterior aortopulmonary window ( Figure 3). Transesophageal EUS-guided fine-needle aspiration (FNA) was performed with five passes, using a 22-gauge needle ( $\bullet$ Figure 4 ). No antibiotic prophylaxis was given. There were no immediate complications. Cytological examination subsequently revealed this to be benign lymphoid tissue.

Five days later, the patient developed chest pain, fevers, and an elevated white blood cell count. Chest computed tomography revealed inflammatory changes in the posterior mediastinal fat abutting the T5-T7 vertebral bodies ( $\bullet$ Figure 5 ). Four sets of blood cultures grew Gemella morbillorum. Thoracic spine magnetic

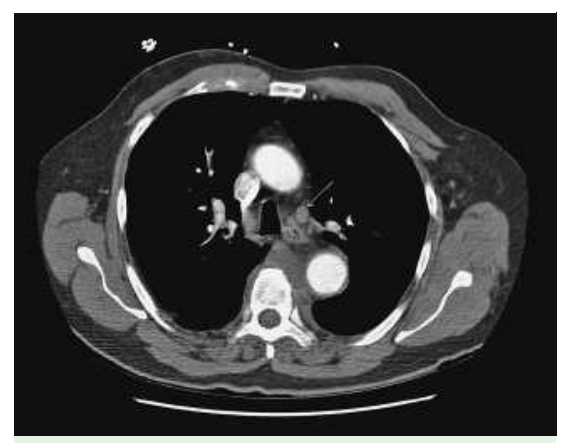

Figure 5 Computed tomographic scan showing posterior mediastinal inflammatory changes extending from the posterior aortopulmonary lymph node (arrow), which had undergone EUS-FNA, to the vertebral bodies at the same level. Note the new inflammatory changes anterior to the vertebral body, which has displaced the aorta to the left.

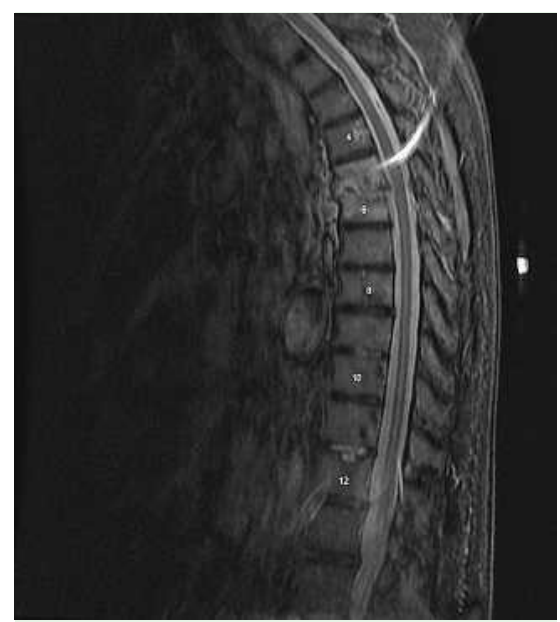

Figure 6 Magnetic resonance imaging scan showing vertebral disk destruction at level T5/ 6. There is also increased signal in T5 and T6, consistent with osteomyelitis.

resonance imaging 6 weeks after the EUS-FNA revealed diskitis and osteomyelitis at T5/6 ( $\bullet$ Figure 6 ). The patient was successfully treated with intravenous ceftriaxone for a total of 12 weeks, and then with oral amoxicillin for several months until all the symptoms and radiographic changes had resolved.

This is the first reported case of transesophageal EUS-FNA of a posterior mediastinal lymph node causing mediastinitis and osteomyelitis. The mediastinitis was probably caused by seeding of the target lymph node by an FNA needle contaminated by G. morbillorum, a facultative, anaerobic, aerotolerant, Gram-positive coccus which is a natural inhabitant of the human oropharynx [1].

- Table 1 summarizes the clinical details of the seven previously reported cases of mediastinitis caused by transesophageal EUS-FNA, as well as this present case [2 - 
Table 1 Reported cases of mediastinitis as a complication of transesophageal endoscopic ultrasound-guided fine-needle aspiration (FNA)

\begin{tabular}{|c|c|c|c|c|c|c|}
\hline Author(s) [ref. no.] & Year & Lesion biopsied & FNA or Trucut & Antibiotics & Complications & Management \\
\hline Ryan et al. [2] & 2002 & Cyst & FNA & Yes & $\begin{array}{l}\text { Incidental Candida organisms } \\
\text { found at resection }\end{array}$ & Thoracotomy \\
\hline Wildi et al. [3] & 2003 & Cyst (solid-appearing) & FNA and Trucut & No & Mediastinitis and sepsis & Thoracotomy \\
\hline Annema et al. [4] & 2003 & Cyst & FNA & No & $\begin{array}{l}\text { Mediastinitis (Streptococcus } \\
\text { pneumoniae) }\end{array}$ & Thoracotomy \\
\hline Westerterp et al. [5] & 2004 & Cyst (solid-appearing) & FNA & No & Mediastinitis & $\begin{array}{l}\text { Endoscopic } \\
\text { fenestration }\end{array}$ \\
\hline Varadarajulu et al. [6] & 2004 & Cyst & Trucut & No & Mediastinitis & Thoracotomy \\
\hline Pai \& Page [7] & 2005 & Mass (teratoma) & FNA & No & Mediastinitis & Thoracotomy \\
\hline Will et al. [8] & 2005 & $\begin{array}{l}\text { Lymph node (malig- } \\
\text { nant) }\end{array}$ & FNA & No & $\begin{array}{l}\text { Mediastinitis and esophago- } \\
\text { mediastinal fistula }\end{array}$ & $\begin{array}{l}\text { Endoscopic } \\
\text { treatment and } \\
\text { antibiotics }\end{array}$ \\
\hline Savides et al. & 2006 & Lymph node (benign) & FNA & No & $\begin{array}{l}\text { Mediastinitis and osteomyeli- } \\
\text { tis (Gemella morbillorum) }\end{array}$ & Antibiotics \\
\hline
\end{tabular}

8]. Five of these were mediastinal cysts, and this has led to the recommendation that EUS-FNA should be avoided in cases where there is clearly a posterior mediastinal cyst, and that antibiotics should be given if an unsuspected cyst is aspirated. Two of these cases reported mediastinitis after EUS-FNA of mediastinal lymph nodes.

Endosonographers should be aware that mediastinitis can occur after transesophageal EUS-FNA of any solid posterior mediastinal lesion, and not only where the lesion is cystic.

\section{Acknowlegdment \\ $\nabla$}

This abstract was presented in part as a poster at EUS 2006 in Amsterdam, 30 June 2006.

Endoscopy_UCTN_Code_CPL_1AL_2AF
T. J. Savides ${ }^{1}$, D. Margolis ${ }^{2}$,

K. M. Richman ${ }^{3}$, V. Singh ${ }^{1}$

1 Division of Gastroenterology, University of California, San Diego, California, USA

2 Division of Infectious Diseases, University of California, San Diego, California, USA

3 Department of Radiology, University of California, San Diego, California, USA

\section{References}

1 Valipour A, Koller H, Setinek U, Burghuber $O C$. Pleural empyema associated with Gemella morbillorum: report of a case and review of the literature. Scand J Infect Dis 2005; 37: $378-381$

2 Ryan AG, Zamvar $V$, Roberts SA. Iatrogenic candidal infection of a mediastinal foregut cyst following endoscopic ultrasound-guided fine-needle aspiration. Endoscopy 2002; 34: $838-839$

3 Wildi SM, Hoda RS, Fickling $W$ et al. Diagnosis of benign cysts of the mediastinum: the role and risks of EUS and FNA. Gastrointest Endosc 2003; 58: $362-368$

4 Annema JT, Veselic M, Versteegh MI, Rabe KF. Mediastinitis caused by EUS-FNA of a bronchogenic cyst. Endoscopy 2003; 35: $791-793$

5 Westerterp M, van den Berg JG, van Lanschot $J J$, Fockens $P$. Intramural bronchogenic cysts mimicking solid tumors. Endoscopy 2004 36: $1119-1122$
6 Varadarajulu S, Fraig M, Schmulewitz $N$ et al. Comparison of EUS-guided 19-gauge Trucut needle biopsy with EUS-guided fine-needle aspiration. Endoscopy 2004; 36: 397-401

7 Pai KR, Page RD. Mediastinitis after EUSguided FNA biopsy of a posterior mediastinal metastatic teratoma. Gastrointest Endosc 2005; 62: 980-981

8 Will U, Meyer F, Bosseckert H. Successful endoscopic management of iatrogenic mediastinal infection and subsequent esophagomediastinal fistula, following endosonographically guided fine-needle aspiration biopsy. Endoscopy 2005; 37: 88-90

Bibliography

DOI 10.1055/s-2007-966157

Endoscopy 2007; 39: E123-E124

(c) Georg Thieme Verlag KG Stuttgart · New York . ISSN 0013-726X

Corresponding author

T. J. Savides, MD

UCSD Gastroenterology

9500 Gilman Drive

Mail Code 0063

La Jolla

California 92093-0063

USA

Fax: +1-858-792-9267

tsavides@ucsd.edu 